\title{
Synthesis of inter-crystalline mesoporous ZSM-5 generated by self-interlocked MFI nanosheet stacks
}

\author{
Ruicong Wei, Hong Yang* and Dongke Zhang
}

Centre for Energy (M473) and School of Mechanical and Chemical Engineering (M050)

The University of Western Australia

35 Stirling Highway, Crawley, WA 6009, Australia

* Corresponding author:

Tel.: 61-8-6488 3064

Fax: 61-8-6488 3132

E-mail address: Hong.Yang@uwa.edu.au 


\begin{abstract}
Aimed to systematically investigate the possibility of using an amphiphilic surfactant, namely $\mathrm{C}_{22-66} \mathrm{Br}_{2}$, as a sole template to synthesise mesoporous ZSM-5 through the manipulation of synthesis conditions, the present work revealed that the $\mathrm{NaOH}$ concentration ([NaOH]$)$ in the precursor solution played a predominant role in the formation of both microporous and mesoporous structures in the ZSM-5 products. A higher $[\mathrm{NaOH}]$ was required to facilitate the formation of micropores for ZSM-5 with lower Si/Al ratios under given synthesis conditions. The higher $[\mathrm{NaOH}]$ was, the greater the crystallinity and micropore volume were found in the product of any given $\mathrm{Si} / \mathrm{Al}$ ratio. $[\mathrm{NaOH}]$ also played a crucial role in the formation of ZSM-5 nanosheet stacks, the structural ordering within these stacks, and the assembly of these stacks. Increasing $[\mathrm{NaOH}]$ at a given $\mathrm{Si} / \mathrm{Al}$ ratio resulted in the formation of the ordered nanosheets stacks, which could grow in a self-interlocked manner in an optimum $[\mathrm{NaOH}]$ range. All experimental evidence converged to prove that these self-interlocked ordered nanosheet stacks (SI-ONS's) were responsible for the inter-crystalline mesopores observed in the ZSM5 products. This study showed that there is a common optimum $[\mathrm{NaOH}]$ range which supports the formation of both microporous and mesoporous structures in ZSM-5. The precursor composition domain for the ternary $\mathrm{NaOH}-\mathrm{SiO}_{2}-\mathrm{AlO}_{1.5}$ system to produce mesoporous ZSM5 was established, providing an important guiding tool to enable the synthesis of ZSM-5 with desired structural properties and $\mathrm{Si} / \mathrm{Al}$ ratios ranging from 85 to 15 .
\end{abstract}




\section{Introduction}

The ZSM-5 with MFI framework ${ }^{1}$ has been widely used in a diverse range of applications, especially as catalyst or catalyst support in petrochemical processing and fine chemical productions. This is due to the combination of the unique microporous structure of ZSM-5 and its tuneable chemical properties that can be regulated by varying $\mathrm{Si} / \mathrm{Al}$ ratios and types of extra-framework cations ${ }^{2-8}$. However, the micropores in ZSM-5 are typically less than $0.6 \mathrm{~nm}$, which limits its applicability towards processes and reactions involving bulky molecules. In order to extend ZSM-5's capabilities to applications involving large molecules, numerous efforts have been made towards the creation of mesoporous ZSM-5. ${ }^{4,}$, 8-23 Most of the reported synthesis strategies to produce mesoporous ZSM-5 involve the use of dual templates, that is, a primary template, typically tetrapropylammonium hydroxide (TPAOH), to direct the formation of microporous structure of MFI framework, and a secondary template to generate mesopores. ${ }^{4,5,8-23}$ Although this method has been very successful in creating mesopores in the resulting ZSM-5, it falls short in achieving controllable mesopore structures of the ZSM-5 products with well-preserved micropores and chemical properties.

Ryoo and his co-workers ${ }^{24}$ pioneered the use of a di-quaternary ammonium-type surfactant, $\mathrm{C}_{22} \mathrm{H}_{45}-\mathrm{N}^{+}\left(\mathrm{CH}_{3}\right)_{2}-\mathrm{C}_{6} \mathrm{H}_{12}-\mathrm{N}^{+}\left(\mathrm{CH}_{3}\right)_{2}-\mathrm{C}_{6} \mathrm{H}_{13}\left(\mathrm{Br}^{-}\right)_{2} \quad\left(\mathrm{C}_{22-6-6} \mathrm{Br}_{2}\right)$, as a bi-functional structure directing agent, and successfully synthesised ZSM-5 of unique nanosheet stacks. With its hydrophilic head functioning as the structural template for forming MFI frameworks, $\mathrm{C}_{22-6-6} \mathrm{Br}_{2}$ promoted the formation of highly ordered thin stacks of ZSM-5 nanosheets along the a-c dimensions, but allowed only limited crystal growth along the b-dimension due to the steric effect of hydrophobic long chain tail of the template. Typically, the nanosheet stacks formed consist of 2-3 MFI structural building units corresponding to 1.5-2.0 nm thickness along the b dimension. ${ }^{24,25}$ The ZSM-5 product possessing the unique nanosheet stacks was found to also support a significant volume of mesopores. These mesopores were believed to have resulted from the spacing between nanosheets within a stack. ${ }^{24}$ In addition, mesopores could also be created by post synthesis treatment to nanosheet stacks via a so-called pillaring process, in which silica pillars between the nanosheets within a stack were introduced to support the formation of inter-crystalline mesopores. ${ }^{25,26}$ However, the pillaring process not only resulted in the decreased micropore volume, but also reduced the external acid sites due to the reaction with silica at the surface $\mathrm{Al}$ sites. ${ }^{25}$ Therefore, it is concluded that from the perspective of preserving the intrinsic microporous structure and acid sites in the synthesized 
ZSM-5 products, it is more desirable to generate mesopores during the formation and assembly process of nanosheet stacks rather than by the post synthesis treatment.

Upon a close examination of the microstructures of ZSM-5 with nanosheet stacks, it is clear that the nanosheet stacks can take the form of complex secondary 3D morphologies through self-assembly depending on the synthesis conditions. It is anticipated that the so-called intercrystalline mesopores can be generated when two nanosheet stacks formed in a somewhat interlocked manner, creating organised microporous structures where stacks meet. Following this hypothesis, extensive literature studies and analysis of microstructural characteristics and structural properties of a wide range of ZSM-5 products have been carried out. While it is obvious that the microstructural characteristics of a ZSM-5 product is highly dependent on the synthesis conditions, the $\mathrm{OH}^{-}$concentration $\left(\left[\mathrm{OH}^{-}\right]\right)$in the precursor clearly plays the most significant role, among other synthesis condition parameters, in controlling the microstructure development of ZSM-5 products at three levels. Firstly, $\mathrm{OH}^{-}$plays a key role in the formation of the highly crystalline microporous structure in ZSM-5. The key function of $\mathrm{OH}^{-}$is to support the mineralization of silica and alumina in the precursor. Consequently, it is not difficult to appreciate that the formation of crystalline microporous structure in ZSM-5 is highly dependent on the $\mathrm{OH}^{-}$concentration $\left(\left[\mathrm{OH}^{-}\right]\right)$in the precursor. ${ }^{27-29}$ It is anticipated that a minimum $\left[\mathrm{OH}^{-}\right]$is required to support the formation of highly crystalline microporous framework structure under a given synthesis condition. It is also expected that a higher $\left[\mathrm{OH}^{-}\right]$ is needed to enable the formation of microporous structure in products with lower $\mathrm{Si} / \mathrm{Al}$ due to the strong $\mathrm{Al}-\mathrm{OH}^{-}$interaction in the precursor. ${ }^{27-29}$ Secondly, $\mathrm{OH}^{-}$is believe to play a key role in influencing the morphological features of the ZSM-5 products, and this is also believed to be directly associated with the packing of the surfactant itself in the precursor solution. It has also been found that a range of amphiphilic surfactants such as cetyl trimethylammonium bromide (CTAB) can arrange into various forms of mesophases of different packing factors. ${ }^{30}$ It was revealed that these surfactants could undergo a transformation from mesophase of lower to higher packing such as from hexagonal to lamella mesophase with increasing $\left[\mathrm{OH}^{-}\right]$, temperature or surfactant concentration. ${ }^{30}$ The bi-functional structure directing agent of $\mathrm{C}_{22-6-6} \mathrm{Br}_{2}$ is a type of amphiphilic surfactant. It is thus hypothesized that $\mathrm{C}_{22-6-6} \mathrm{Br}_{2}$ could also form mesophases of different packing factors depending on $\left[\mathrm{OH}^{-}\right]$in the precursor, and it is the lamella mesophase of the $\mathrm{C}_{22-6-6} \mathrm{Br}_{2}$ that acts as the structure directing template to dictate the formation of the nanosheet stacks observed in the ZSM-5 products. Finally, $\mathrm{OH}^{-}$is also believed to play a balancing role in 
controlling the size (the a-c dimensions) of ZSM-5 nanosheet stacks. The size of the nanosheet stacks would then affect the assembly of them when forming the complex interlocked stacks. It is believed that this final microstructure has a strong impact on the mesopore volume in the final ZSM-5 products.

This present work was aimed to synthesis mesoporous ZSM-5 products with highly crystalline microporous structure and well-preserved acid sites using bi-functional $\mathrm{C}_{22-6-6} \mathrm{Br}_{2}$ as structural directing templates. The experimental program was designed to delineate the crucial roles played by $\left[\mathrm{OH}^{-}\right]$of the precursor solution in the formation of mesoporous ZSM-5, and to establish the optimum $\left[\mathrm{OH}^{-}\right]$range to produce ZSM-5 with desired structural properties. Since $\mathrm{OH}^{-}$cannot be introduced to the precursor solution alone, but commonly in the form of $\mathrm{NaOH}$, this work systematically investigated the ZSM-5 synthesis under different conditions and established the relationship between $[\mathrm{NaOH}]$ and the structural properties of resulted ZSM-5 products, shedding lights on the formation mechanisms of micropores and mesopores in the ZSM-5 synthesised.

\section{Experimental Methods and Procedures}

\subsection{Chemicals for material synthesis}

1-bromohexane (>98.0 \%), N,N,N',N'-tetramethyl-1,6-diaminohexane $\quad(>98.0 \%), \quad 1$ bromodocosane ( $>98.0 \%$ ) were acquired from TCI, Tokyo Kasei. Acetonitrile ( $\geq 99.9 \%$ ), toluene $(\geq 99.9 \%)$ and diethyl ether $(\geq 99.7 \%)$ were purchased from RCI Labscan Limited. Aluminium sulphate hydrate $\left(\mathrm{Al}_{2}(\mathrm{SO})_{4} \cdot 14 \mathrm{H}_{2} \mathrm{O}, 100 \%\right)$ and tetraethyl orthosilicate (TEOS, 98\%) were supplied by Chem-Supply Pty Ltd and Acros Organics BVBA, respectively. Sodium hydroxide ( $\geq 99.9 \%)$, sodium sulphate $(\geq 99.9 \%)$ and sodium bromide $(\geq 99.9 \%)$ were obtained from Merck KGaA while sulphuric acid solution (40 wt\% in water) was purchased from Fluka Chemical Corp. Deionized (DI) water was used in all synthesis.

\subsection{Preparation of Structure Directing Agent}

The bi-functional surfactant, $\mathrm{C}_{22} \mathrm{H}_{45}-\mathrm{N}^{+}\left(\mathrm{CH}_{3}\right)_{2}-\mathrm{C}_{6} \mathrm{H}_{12}-\mathrm{N}^{+}\left(\mathrm{CH}_{3}\right)_{2}-\mathrm{C}_{6} \mathrm{H}_{13}\left(\mathrm{Br}^{-}\right)_{2}\left(\mathrm{C}_{22-6-6} \mathrm{Br}_{2}\right)$, was synthesized following a two-step procedure reported by Roo and his co-workers ${ }^{24}$.

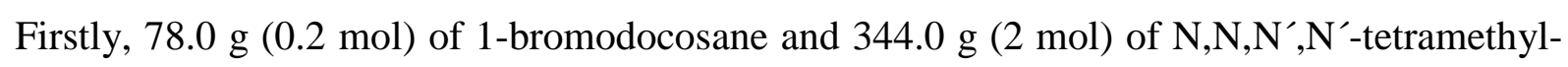
1,6-diaminohexane were dissolved in $2000 \mathrm{~mL}$ of acetonitrile/toluene mixture $(1: 1 \mathrm{vol} / \mathrm{vol})$ and heated to and held at $343 \mathrm{~K}$ for $24 \mathrm{~h}$. After that, the solution was cooled to room 
temperature and the solid product was filtered, washed with diethyl ether, and dried in at 333 $\mathrm{K}$ for $12 \mathrm{~h}$. Subsequently, $112.0 \mathrm{~g}(0.2 \mathrm{~mol})$ of the intermediate product, $\mathrm{C}_{22} \mathrm{H}_{45}-\mathrm{N}^{+}\left(\mathrm{CH}_{3}\right)_{2}{ }^{-}$ $\mathrm{C}_{6} \mathrm{H}_{12}-\mathrm{N}\left(\mathrm{CH}_{3}\right)_{2} \mathrm{Br}^{-}$, produced and $52.8 \mathrm{~g}(0.2 \mathrm{~mol})$ of 1-bromohexane were dissolved in 600 $\mathrm{mL}$ acetonitrile and refluxed for $24 \mathrm{~h}$. After cooling to room temperature, the final surfactant product was filtered, washed with diethyl ether, dried at $333 \mathrm{~K}$ for $12 \mathrm{~h}$, and stored for use.

\subsection{ZSM-5 synthesis procedures}

A typical ZSM-5 synthesis procedure involved the followed steps:

(1) $0.5 \mathrm{~mol}$ of the prepared template was dissolved in deionised water to form a $10 \mathrm{wt} \%$ template solution.

(2) A desired amount (in mol) of $\mathrm{NaOH}$ and 10 mol TEOS were then added to the template solution. The resultant solution (Solution-A) was stirred at $333 \mathrm{~K}$ for $0.5 \mathrm{~h}$. This step was designed for two purposes: firstly, to use $\mathrm{OH}^{-}$to hydrolyse and solubilize TEOS to release the reactive silicates; and secondly to allow the reactive silicates to interact with the surfactant to form primary aggregates in order to facilitate nucleation of the microporous structure.

(3) Separately, a desired amount (in mol) of $\mathrm{Al}_{2}\left(\mathrm{SO}_{4}\right)_{3} \cdot 14 \mathrm{H}_{2} \mathrm{O}$ and $1.65 \mathrm{~mol}$ of $\mathrm{H}_{2} \mathrm{SO}_{4}$ were mixed while being dissolved in deionized water (Solution B). This step was to ensure the preparation of a homogeneous aluminium source solution.

(4) Solution-B was then added to Solution-A drop-wise to form the final colloidal solution, which is designated as the precursor in this work. The detailed composition of the precursor is shown in Table 1.

(5) The precursor was further stirred at $333 \mathrm{~K}$ for $6 \mathrm{~h}$. This is an important aging process for nucleation of the product phase. In addition, the surfactants can also assemble and aggregate in a certain manner to form specific mesophase during this aging process.

(6) After aging, the precursor was transferred to a Teflon-coated stainless-steel autoclave and heated to $423 \mathrm{~K}$ and maintained for $120 \mathrm{~h}$ with the autoclave set to tumbling at 60 r.p.m to allow crystallization and growth of microporous structures, and formation of mesoporous structure to take place should the synthesis conditions be favourable. 
(7) After crystallization, the autoclave was removed from the oven and quenched with cold water to ambient temperature. The $\mathrm{pH}$ was measured for the final solution before the solid product was recovered and washed by centrifugation. Finally, the product was dried in an air oven at $343 \mathrm{~K}$ for $14 \mathrm{~h}$. This product is referred to as the 'as-synthesised product' in this paper.

(8) The dried product was calcined in air at $813 \mathrm{~K}$ for $4 \mathrm{~h}$ to remove the surfactant. The term 'product' used in this paper refers to the calcined product unless otherwise specified.

Table1 List of precursor molar compositions of all synthesized samples and molar ratios of $\mathrm{NaOH} / \mathrm{SiO}_{2}$ in the precursor

\begin{tabular}{|c|c|c|c|c|c|c|c|}
\hline & $\mathrm{NaOH}$ & $\mathrm{Al}_{2}\left(\mathrm{SO}_{4}\right)_{3} \cdot 14 \mathrm{H}_{2} \mathrm{O}$ & TEOS & $\mathrm{C}_{22-6-6} \mathrm{Br}_{2}$ & $\mathrm{H}_{2} \mathrm{SO}_{4}$ & $\mathrm{H}_{2} \mathrm{O}$ & $\mathrm{NaOH} / \mathrm{SiO}_{2}{ }^{\mathrm{a}}$ \\
\hline Si/Al-87-40OH & 40 & 0.57 & 100 & 5 & 16.5 & 4000 & 0.07 \\
\hline $\mathrm{Si} / \mathrm{Al}-\mathbf{8 7 - 5 0 O H}$ & 50 & 0.57 & 100 & 5 & 16.5 & 4000 & 0.17 \\
\hline $\mathrm{Si} / \mathrm{Al}-\mathbf{8 7}-60 \mathrm{OH}$ & 60 & 0.57 & 100 & 5 & 16.5 & 4000 & 0.27 \\
\hline Si/Al-87-70OH & 70 & 0.57 & 100 & 5 & 16.5 & 4000 & 0.37 \\
\hline Si/Al-87-80OH & 80 & 0.57 & 100 & 5 & 16.5 & 4000 & 0.47 \\
\hline$\overline{\mathrm{Si} / \mathrm{Al}-50-40 \mathrm{OH}}$ & 40 & 1 & 100 & 5 & 16.5 & 4000 & 0.07 \\
\hline $\mathrm{Si} / \mathrm{Al}-\mathbf{5 0}-50 \mathrm{OH}$ & 50 & 1 & 100 & 5 & 16.5 & 4000 & 0.17 \\
\hline $\mathrm{Si} / \mathrm{Al}-\mathbf{5 0}-60 \mathrm{OH}$ & 60 & 1 & 100 & 5 & 16.5 & 4000 & 0.27 \\
\hline Si/Al-50-70OH & 70 & 1 & 100 & 5 & 16.5 & 4000 & 0.37 \\
\hline $\mathrm{Si} / \mathrm{Al}-\mathbf{5 0}-80 \mathrm{OH}$ & 80 & 1 & 100 & 5 & 16.5 & 4000 & 0.47 \\
\hline Si/Al-50-90OH & 90 & 1 & 100 & 5 & 16.5 & 4000 & 0.57 \\
\hline$\overline{\mathrm{Si} / \mathrm{Al}-30-40 \mathrm{OH}}$ & 40 & 1.67 & 100 & 5 & 16.5 & 4000 & 0.07 \\
\hline $\mathrm{Si} / \mathrm{Al}-\mathbf{3 0}-50 \mathrm{OH}$ & 50 & 1.67 & 100 & 5 & 16.5 & 4000 & 0.17 \\
\hline Si/Al-30-60OH & 60 & 1.67 & 100 & 5 & 16.5 & 4000 & 0.27 \\
\hline Si/Al-30-70OH & 70 & 1.67 & 100 & 5 & 16.5 & 4000 & 0.37 \\
\hline Si/Al-30-80OH & 80 & 1.67 & 100 & 5 & 16.5 & 4000 & 0.47 \\
\hline Si/Al-15-40OH & 40 & 3.33 & 100 & 5 & 16.5 & 4000 & 0.07 \\
\hline $\mathrm{Si} / \mathrm{Al}-\mathbf{1 5}-50 \mathrm{OH}$ & 50 & 3.33 & 100 & 5 & 16.5 & 4000 & 0.17 \\
\hline $\mathrm{Si} / \mathrm{Al}-\mathbf{1 5}-60 \mathrm{OH}$ & 60 & 3.33 & 100 & 5 & 16.5 & 4000 & 0.27 \\
\hline $\mathrm{Si} / \mathrm{Al}-\mathbf{1 5}-70 \mathrm{OH}$ & 70 & 3.33 & 100 & 5 & 16.5 & 4000 & 0.37 \\
\hline $\mathrm{Si} / \mathrm{Al}-\mathbf{1 5}-80 \mathrm{OH}$ & 80 & 3.33 & 100 & 5 & 16.5 & 4000 & 0.47 \\
\hline $\mathrm{Si} / \mathrm{Al}-\mathbf{1 5}-70 \mathrm{OH}$ & 90 & 3.33 & 100 & 5 & 16.5 & 4000 & 0.57 \\
\hline Si/Al-15-80OH & 100 & 3.33 & 100 & 5 & 16.5 & 4000 & 0.67 \\
\hline
\end{tabular}

${ }^{\mathrm{a}}$ The amount of $\mathrm{NaOH}=\mathrm{NaOH}$ added $-\mathrm{NaOH}$ neutralized stoichiometrically by the $\mathrm{H}_{2} \mathrm{SO}_{4}$ added; $\mathrm{SiO}_{2}$ is the equivalent amount from the TEOS added assuming it was fully hydrolysed. 


\subsection{Characterization of synthesized products}

Powder X-ray diffraction (XRD) patterns of the products were obtained using a Panalytical Empyrean X-ray Diffractometer equipped with $\mathrm{Cu} \mathrm{K \alpha}$ radiation (40 kV, $40 \mathrm{~mA})$. Small-angle X-ray scattering (SAXS) patterns were obtained using an Anton Paar 'SAXSess' equipped with charge-coupled device (CCD) in a sealed x-ray tube. Scanning electron microscopy (SEM) imaging analysis was performed using a Zeiss 1555 VP-FESEM instrument operating at $3 \mathrm{kV}$. Transmission electron microscopy (TEM) images were taken with a JEOL 2100 at an accelerating voltage of $200 \mathrm{kV}$.

$\mathrm{N}_{2}$ adsorption/desorption isotherms were measured at liquid $\mathrm{N}_{2}$ temperature using a Micromeritics Tristar II 3020 volumetric analyser. Before a typical measurement, a sample was degassed under vacuum at $473 \mathrm{~K}$ for $14 \mathrm{~h}$. The Brunauer-Emmett-Teller (BET) equation was used to calculate the BET specific surface area ${ }^{31,32}$ from the adsorption data range determined by the method reported by Rouquerol and co-workers. ${ }^{33}$ The micropore volumn, $\mathrm{V}_{\text {micro }}$, was calculated using the t-plot method. The total pore volume was evaluated at $\mathrm{P} / \mathrm{P}_{0}=$ 0.97, allowing the mesopore volume $\mathrm{V}_{\text {meso }}$ to be determined by subtracting the micropore volume from the total pore volume. The mesopore size distribution (PSD) was determined using the Barrett-Joyner-Halenda (BJH) algorithm on the adsorption branch. ${ }^{34}$

The $\mathrm{pH}$ of the colloidal solution after crystallization was measured with a TPS WP-80 Waterproof pH-mV-Temperature Meter.

MAS NMR was used to determine the amount of tetrahedral aluminium incorporated in the ZSM-5 framework. The measurements were performed on a Varian 400 wide-bore NMR spectrometer equipped with two radio frequency (RF) channels. The ${ }^{27}$ Al MAS NMR spectra were recorded at $104.2 \mathrm{MHz}$ at a spinning frequency of $5 \mathrm{k} \mathrm{Hz}$ and a $2.05 \mathrm{~s}$ interval between successive accumulations. Inductively coupled plasma atomic emission spectroscopy (ICPAES) analysis was also carried out to determine the total Si/Al ratio of ZSM-5 products produced. The measurements were carried out using a Thermo Scientific iCAP 6500 Duo system.

\subsection{Summary of synthesis conditions and products}

To investigate the effect of $\mathrm{NaOH}$ addition in the precursor solution on the properties of the final ZSM-5 products, 4 batches of samples with Si/Al ratios of 87, 50, 30 and 15, 
respectively, were synthesized from their corresponding precursor solutions with different amounts of added $\mathrm{NaOH}$, as summarized in Table 1. Keeping the amount of the silica source (TEOS) same in each precursor, the molar ratio of the other chemicals added into the precursor was calculated relative to the number of moles of TEOS. Therefore, at a given Si/Al ratio, $[\mathrm{NaOH}]$ was expressed as the molar ratio of $\mathrm{NaOH} / \mathrm{SiO}_{2}$ throughout this paper. The calculated equivalent molar ratio of $\mathrm{NaOH} / \mathrm{SiO}_{2}$ was also shown in Table 1.

\section{Results and Discussion}

\subsection{General structural properties of a typical ZSM-5 product}

Fig. 1 shows the general structural properties of a typical desired mesoporous ZSM-5 product obtained in this study. Fig. 1A shows the XRD pattern of the product together with the wellrecognized XRD pattern of a conventional ZSM-5 sample, ${ }^{35}$ with main diffraction peaks of the MFI framework structure labelled. The XRD pattern clearly shows the crystalline MFI framework structure, thus confirming that the product was indeed ZSM-5. It is also shown that most of the high intensity diffraction peaks, such as (501), (303), (101) and (103), are associated with crystallographic planes along the a-c dimensions, whilst diffraction peaks associated with crystallographic planes along the b-dimension as seen in the conventional sample are largely absent. This observation is consistent with the morphology of the product as discussed below.

Fig. 1B shows an SEM image of the product revealing the cluster structures made of plates of 200-300 nm in width and assembled in an a self-interlocked manner. The TEM imaging analysis of individual plates found that each plate was comprised of an assembly of several nanosheets of $\sim 2 \mathrm{~nm}$ in thickness as evident in Fig. 1C. Each of the nanosheets was comprised of 3 pentasil building units in the b-dimension of the MFI framework. Several of the nanosheets (in this example, 5 nanosheets) assembled along the b-dimension with equal spacing pillared by the hydrophobic tail of the surfactant. ${ }^{24}$ Furthermore, as clearly evident in the TEM image, the nanosheets formed an orderly assembled nanosheet stack, and these ordered nanosheet stacks (ONS's) typically had a thickness between 20-40 nm. Having identified each plate as an ONS, it is further noticed that in this specific product, many of the ONS's had self-interlocked microstructures as highlighted by dashed circles in Fig. 1C. These unique microstructural features are named in this paper the self-interlocked ordered nanosheet stacks or SI-ONS's. It is believed that these SI-ONS's are responsible for the inter-crystalline 

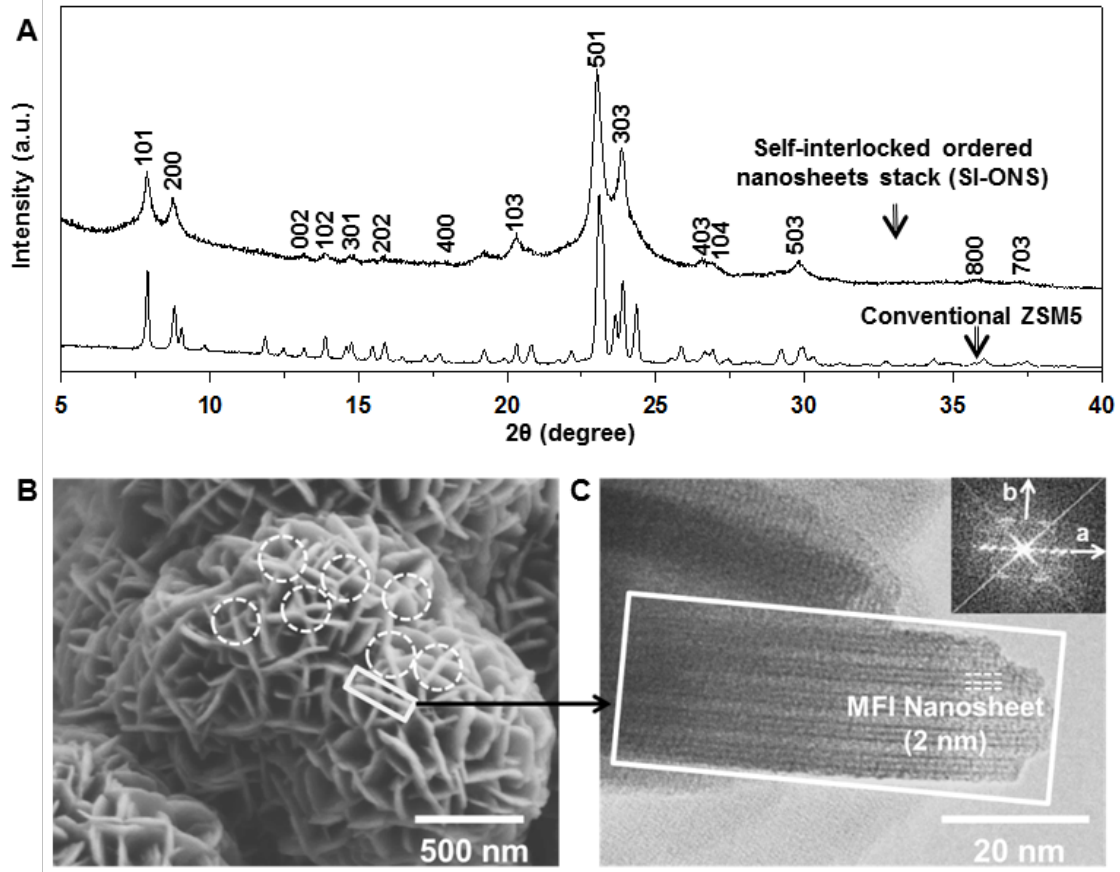

D

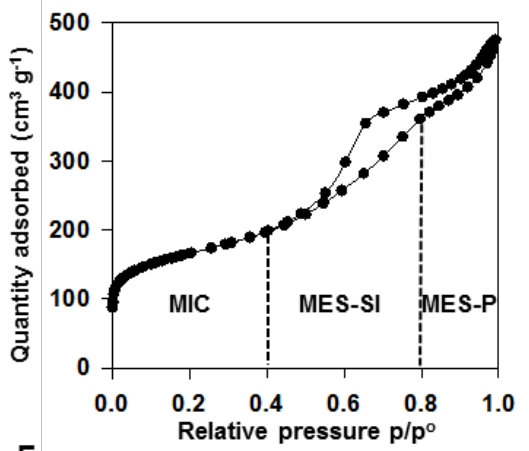

E
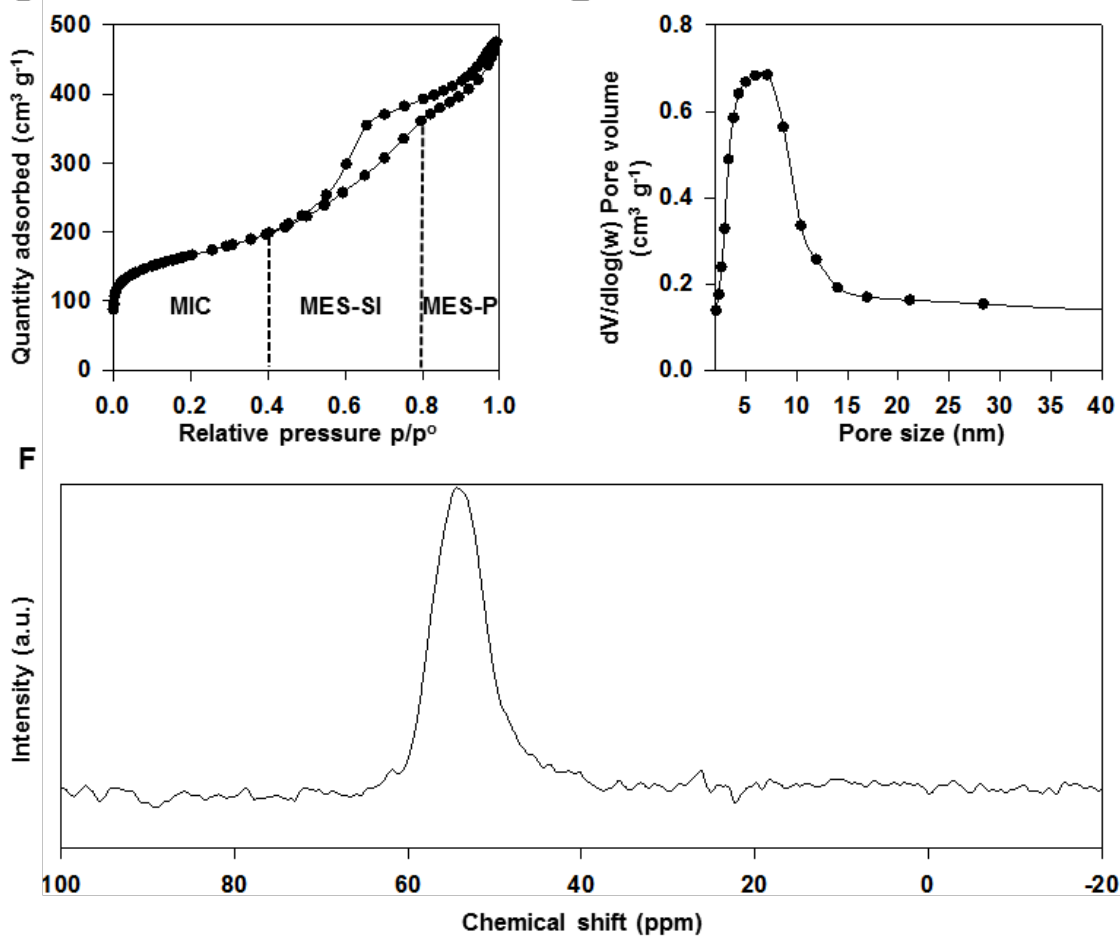

Fig. 1 A composite figure shows the general structural properties of a typical ZSM5 product with most desirable structure. A) XRD pattern; B) a SEM image of the ZSM5 product containing self-interlocked orderred nanosheet stacks (SI-ONS's), the microstructural units as highlited in dashed circles; C) a TEM image of an orderred nanosheet stack (ONS); D) $\mathrm{N}_{2}$ adsorption-desorption isotherm; E) mesopore size distribution estimated using the Barrett-Joyner-Halenda (BJH) method; and F) ${ }^{27} \mathrm{Al}$ NMR spectrum. 
mesopores observed in the product as revealed by the $\mathrm{N}_{2}$ adsorption-desorption isotherms shown in Fig. 1D. Three distinctive types of pores can be observed from the isotherm curves. The region before $\mathrm{p} / \mathrm{p}^{0}=0.42$ where the closure point of the hysteresis loop is located represents type-I physisorption isotherms which are associated with the adsorption-desorption behaviour of micropores; ${ }^{31}$ this micropore region is named MIC. The region between $\mathrm{p} / \mathrm{p}^{\mathrm{o}}=$ 0.42 and 0.8 exhibits type-IV physisorption isotherms with a distinctive hysteresis loop, ${ }^{31}$ suggesting that the product contained mesopores. In addition, this region also displays a type

$\mathrm{H} 2$ hysteresis loop, ${ }^{31}$ indicating the presence of interconnected mesopores. The mesopores in this region are believed to be inter-crystalline mesopores formed at the interlocked area of each SI-ONS. This region is thus named MES-SI, referring to the mesopores originated from SI-ONS's. The region beyond $\mathrm{p} / \mathrm{p}^{0}=0.8$ represents a type H3 hysteresis loop, ${ }^{31}$ revealing the mesopores were believed to be arisen from randomly packed ONS's. This region is thus named as MES-P, in recognition of the mesopores formed due to packing. The corresponding mesopore size distribution (PSD) of this sample calculated using the $\mathrm{BJH}$ method on the adsorption branch is shown in Fig. 1E. The PSD reveals that the product contained mesopores of a relatively broad size distribution peaked at $5.4 \mathrm{~nm}$. Having only one broad PSD peak is somewhat inconsistent with the observation that the sample contains at least two types of mesopores, the inter-crystalline mesopores and packing mesopores. It is known that the BJH method was developed assuming homogeneous pore surfaces and open-ended cylindrical pore structure of the material. ${ }^{34}$ However, the product examined has heterogeneous pore surfaces and the pores are obviously non-cylindrical. Therefore, the PSD obtained by BJH method should only be used to provide an average indicative value of the pore sizes.

The ${ }^{27} \mathrm{Al}$ MAS NMR analysis performed on the product allowed the amount of tetrahedral Al incorporated in the MFI framework to be determined. As shown in Fig. 1F, the NMR spectrum appears to have only a single distinctive peak at 55 ppm, which is associated with the tetrahedrally coordinated $\mathrm{Al}$ species. No NMR peak at $0 \mathrm{ppm}$, typically associated with the octahedrally coordinated $\mathrm{Al}$ species, is observed. The NMR result confirmed that most of the $\mathrm{Al}$ species were tetrahedrally incorporated into the MFI framework in the product.

\subsection{Effect of $\mathrm{NaOH} / \mathrm{SiO}_{2}$ ratio on the formation of microporous structure}

Fig. 2B shows the powder XRD patterns for a series of as-synthesized products of a nominal $\mathrm{Si} / \mathrm{Al}$ of 50 prepared from precursor solutions of different $\mathrm{NaOH} / \mathrm{SiO}_{2}$ molar ratios. The crystalline patterns obtained are similar to the pattern presented in Fig. 1A, thus confirming 


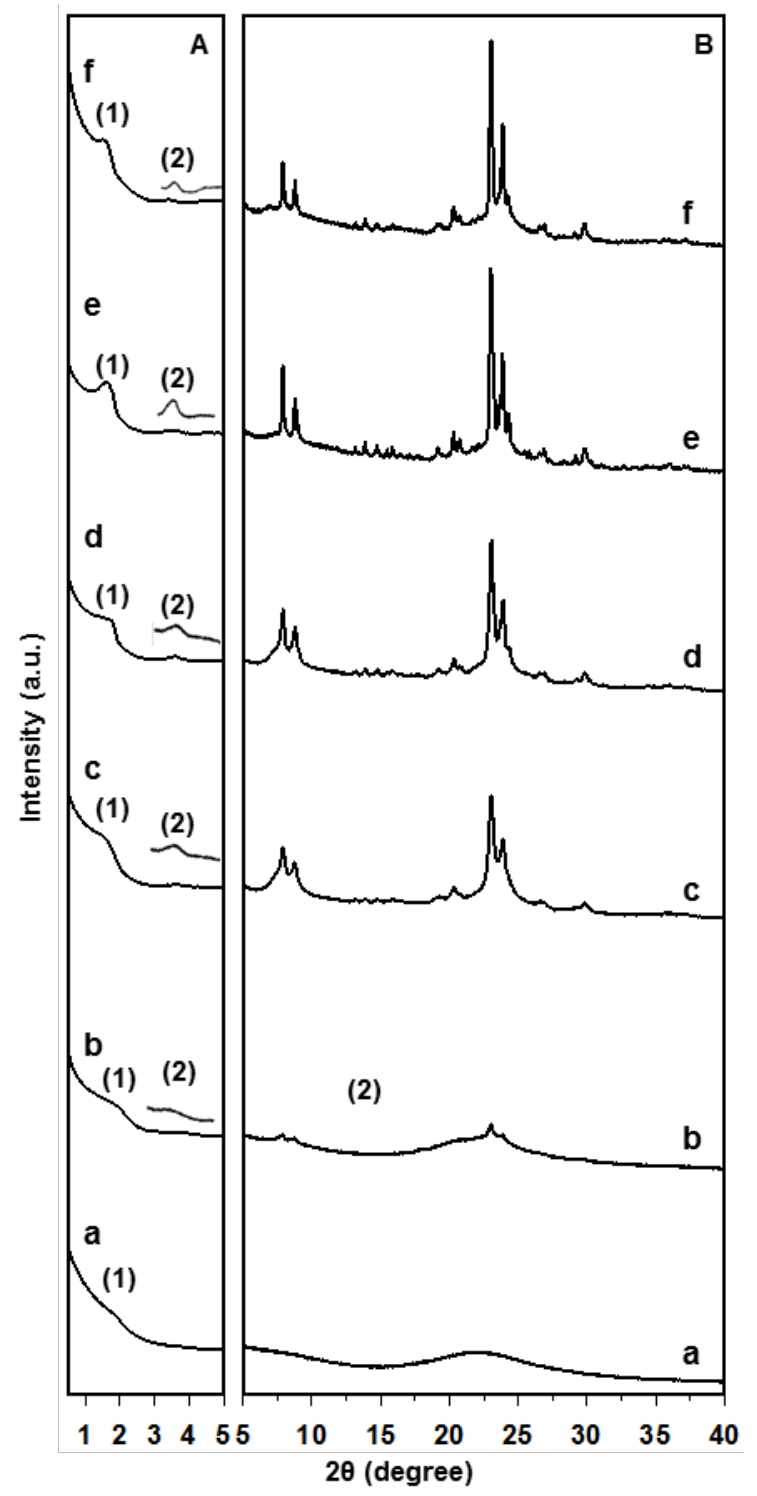

Fig. 2 A) SAXS patterns and B) XRD patterns of as-synthesized products of $\mathrm{Si} / \mathrm{Al}=50$ produced at different $\mathrm{NaOH} / \mathrm{SiO}_{2}$ ratios of (a) 0.07, (b) 0.17, (c) 0.27, (d) 0.37, (e) 0.47 , and (f) 0.57 , respectively.

that the crystalline products are indeed ZSM-5. However, it is obvious that the $\mathrm{NaOH} / \mathrm{SiO}_{2}$ ratio has a significant impact on the crystallinity of the products. At the relatively low $\mathrm{NaOH} / \mathrm{SiO}_{2}$ ratio of 0.07 , the product was of amorphous structure without any characteristic diffraction peaks normally associated with the MFI framework observed as shown in Fig. 2Ba. As the $\mathrm{NaOH} / \mathrm{SiO}_{2}$ ratio was increased to 0.17 , the main diffraction peaks characteristic of the MFI framework started to emerge (Fig. 2B-b). Further increasing the $\mathrm{NaOH} / \mathrm{SiO}_{2}$ ratio from 0.17 to 0.47 saw a progressive increase in the intensity and resolution of the MFI 
diffraction peaks, indicating the formation of continually improved microporous ZSM-5 products as the $\mathrm{NaOH} / \mathrm{SiO}_{2}$ ratio increased. No significant differences were found between the diffraction patterns of the two products synthesised at $\mathrm{NaOH} / \mathrm{SiO}_{2}=0.47$ and 0.57 . It is worth noting that a similar trend was also observed for products of Si/Al ratios of 15, 30 and 87.

The XRD results provide the following important findings:

(1) For a given $\mathrm{Si} / \mathrm{Al}$ ratio, a minimum $\mathrm{NaOH} / \mathrm{SiO}_{2}$ ratio in the precursor solution is required to support the formation of highly crystalline MFI framework structures in the ZSM-5 product under a given synthesis condition.

(2) The crystallinity of the ZSM-5 product improves with increasing the $\mathrm{NaOH} / \mathrm{SiO}_{2}$ ratio under otherwise identical synthesis conditions.

(3) The required minimum $\mathrm{NaOH} / \mathrm{SiO}_{2}$ ratio to form the highly crystalline MFI framework structure in ZSM-5 increases as the Si/Al ratio in the product decreases.

These findings are further supported by the results of the $\mathrm{N}_{2}$ sorption measurements. Fig. $3 \mathrm{~A}$ presents the micropore volumes calculated from the $\mathrm{N}_{2}$ sorption isotherms of the products of $\mathrm{Si} / \mathrm{Al}=50$ synthesised at different $\mathrm{NaOH} / \mathrm{SiO}_{2}$ ratios. Several features could be seen from the micropore volume data: Firstly, the product formed at $\mathrm{NaOH} / \mathrm{SiO}_{2}=0.07$ contained no micropore volume, consistent with the XRD result showing the amorphous nature of the product. Secondly, a rather low $\mathrm{V}_{\text {micro }}$ of $\sim 0.02 \mathrm{~cm}^{3} \mathrm{~g}^{-1}$ was observed for the product at $\mathrm{NaOH} / \mathrm{SiO}_{2}=0.17$ indicating that the MFI framework structure was emerging in the product as also confirmed by the XRD result. Thirdly, as expected, at $\mathrm{NaOH} / \mathrm{SiO}_{2} \geq 0.27$, a more than 5-fold increase in $\mathrm{V}_{\text {micro }}$ was obtained for subsequent products, consistent with the highly crystalline MFI framework structure observed in these products.

Similar dependence of the micropore volume on the $\mathrm{NaOH} / \mathrm{SiO}_{2}$ ratio was also observed for products of other $\mathrm{Si} / \mathrm{Al}$ ratios and the results are plotted in Fig. 3B. Clearly, for a given $\mathrm{Si} / \mathrm{Al}$ ratio, there exists a minimum $\mathrm{NaOH} / \mathrm{SiO}_{2}$ ratio above which a high $\mathrm{V}_{\text {micro }}$ value greater than $0.08 \mathrm{~cm}^{3} \mathrm{~g}^{-1}$ can be obtained for all products. This is again consistent with the findings from the XRD analysis showing the formation of highly crystalline MFI framework structures in these products. In addition, it could also be seen that the lower the Si/Al ratio, the higher this required minimum $\mathrm{NaOH} / \mathrm{SiO}_{2}$ ratio is to ensure the formation of highly crystalline products. 

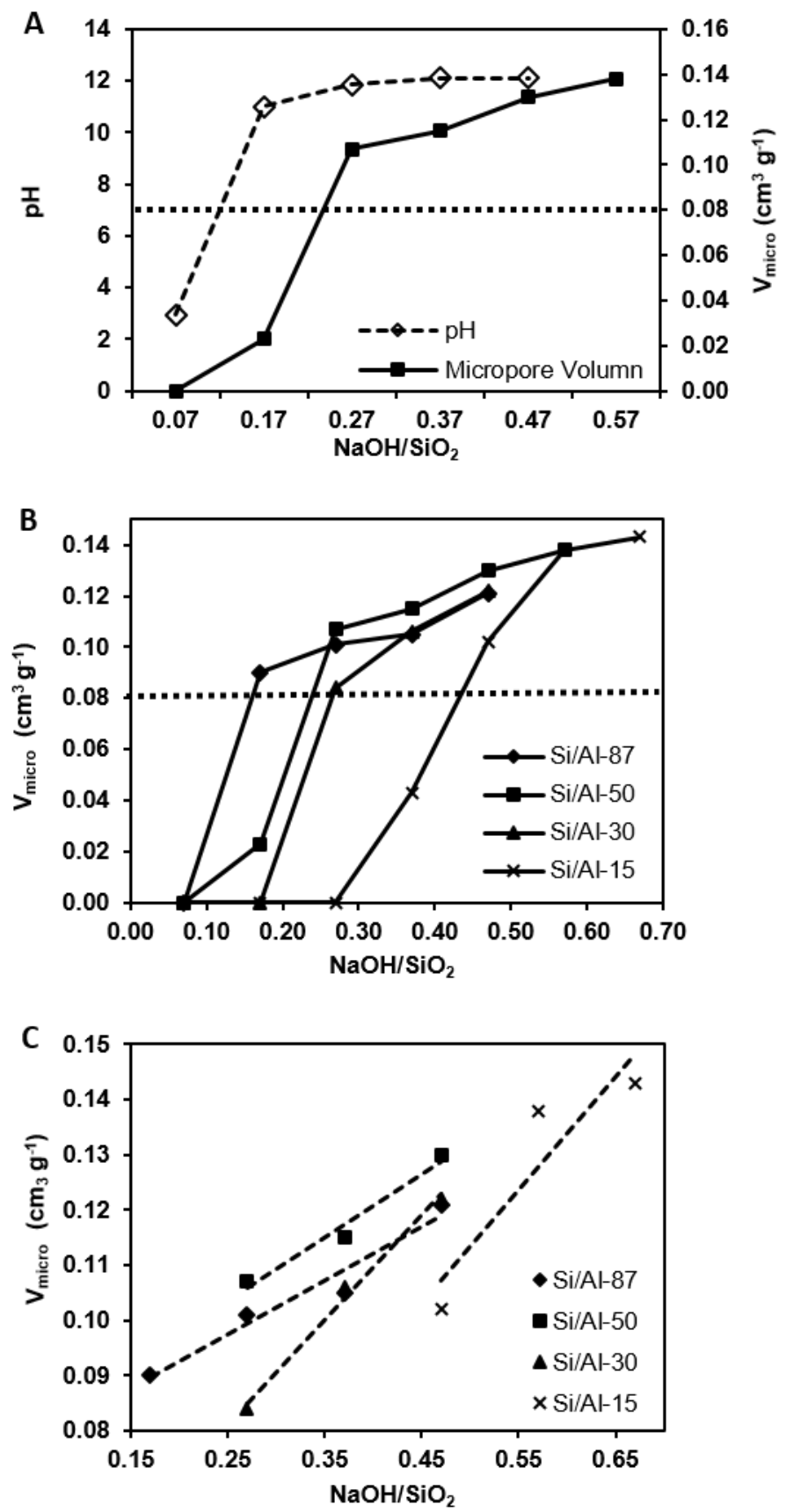

Fig. 3 A) Plots of $\mathrm{pH}$ and micropore volume $\left(\mathrm{V}_{\text {micro }}\right)$ versus $\mathrm{NaOH} / \mathrm{SiO}_{2}$ for products of $\mathrm{Si} / \mathrm{Al}=50$; B) Plots of $\mathrm{V}_{\text {micro }}$ versus $\mathrm{NaOH} / \mathrm{SiO}_{2}$ for products of different $\mathrm{Si} / \mathrm{Al}$ ratios; and $\mathrm{C}$ ) Plots of $\mathrm{V}_{\text {micro }}$ versus $\mathrm{NaOH} / \mathrm{SiO}_{2}$ for highly-crystalline products of different $\mathrm{Si} / \mathrm{Al}$ ratios. 
Furthermore, as shown in Fig. 3C, for all highly-crystallised ZSM-5 products, the $\mathrm{V}_{\text {micro }}$ was found to increase almost linearly with increasing $\mathrm{NaOH} / \mathrm{SiO}_{2}$ ratio in the precursor.

\subsection{Effect of $\mathrm{NaOH} / \mathrm{SiO}_{2}$ on the formation of mesoporous structure}

Typical SEM images of products of $\mathrm{Si} / \mathrm{Al}=50$ produced at different $\mathrm{NaOH} / \mathrm{SiO}_{2}$ ratios from 0.07 to 0.57 are shown in Fig. 4. The corresponding TEM images of selected samples are shown in Fig. 5. These images reveal the remarkable sequence of evolution of the product microstructure from spherical to plate-like aggregates as the $\mathrm{NaOH} / \mathrm{SiO}_{2}$ ratio was increased.

It can be seen that the product produced at a very low $\mathrm{NaOH} / \mathrm{SiO}_{2}$ ratio of 0.07 contained submicron to micron sized spherical aggregates (Fig. 4a and Fig. 5a) with uniform features. A high resolution TEM micrograph (Fig. 5a') further reveals that each spherical aggregate was comprised of nano-domains. This typical amorphous structure agrees well with the XRD finding (Fig. 2B).

As the $\mathrm{NaOH} / \mathrm{SiO}_{2}$ ratio was increased to 0.17 , the product was found to contain loosely packed clusters of highly irregular aggregates (Fig. 4b), but also contained nano-sized particles as seen in the corresponding TEM image (Fig. 5b), which revealed two distinctive types of structural features within the irregular aggregates: one being characterised by wormlike, interconnected channels formed by amorphous structure building unit while the other consisting of tiny crystalline domains of the MFI framework structure (Fig. 5b'), consistent with the observations from the XRD pattern of the product (Fig. 2B-b).

The product formed at $\mathrm{NaOH} / \mathrm{SiO}_{2}=0.27$ contained clusters comprised of aggregated plates distinctively arranged in an interlocked manner as shown in Fig. 4c and Fig. 5c. As discussed in Section 3.1 above, each plate was an ordered nanosheet stack (ONS) (Fig. 5c'). Remarkably, a significant portion of the plates (or ONSs) in this product were in what is called the interlocked format as marked in the insert of Fig. 4c. They are herein named as selfinterlocked ordered nanosheet stacks (SI-ONS’s).

As the $\mathrm{NaOH} / \mathrm{SiO}_{2}$ ratio was increased to 0.37 , the aggregated clusters grew noticeably bigger as the plates within clusters continued to grow along the planar a-c dimensions, as evident in Fig. 4d, although the general microstructural features of this product remained similar to that of the previous product. 

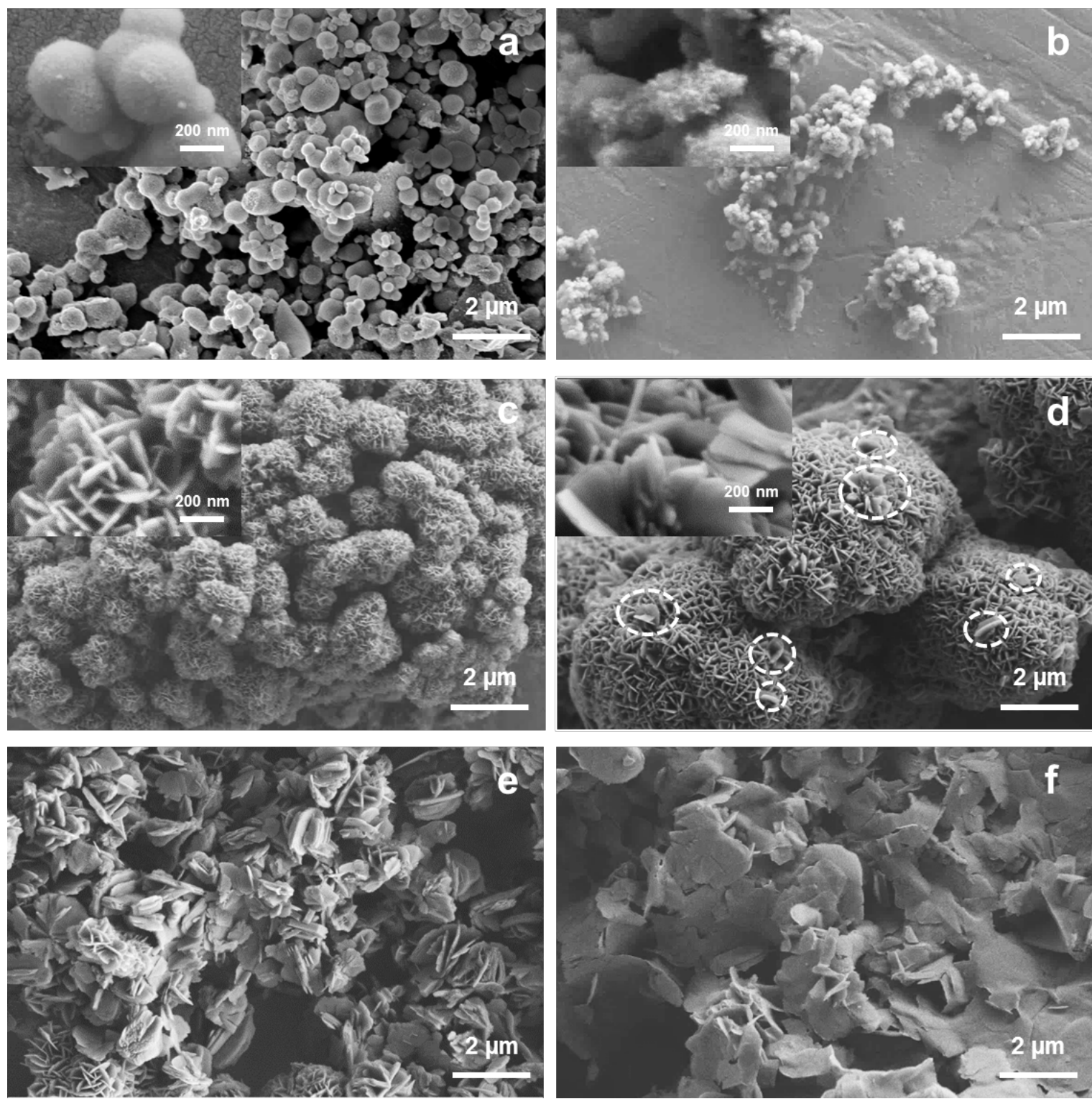

Fig. 4 SEM images of as-synthesized products obtained from precursors of $\mathrm{Si} / \mathrm{Al}=50$ at different $\mathrm{NaOH} / \mathrm{SiO}_{2}$ ratios: (a) 0.07, (b) 0.17, (c) 0.27, (d) 0.37, (d) 0.37, (e) 0.47, and (f) 0.57 . 

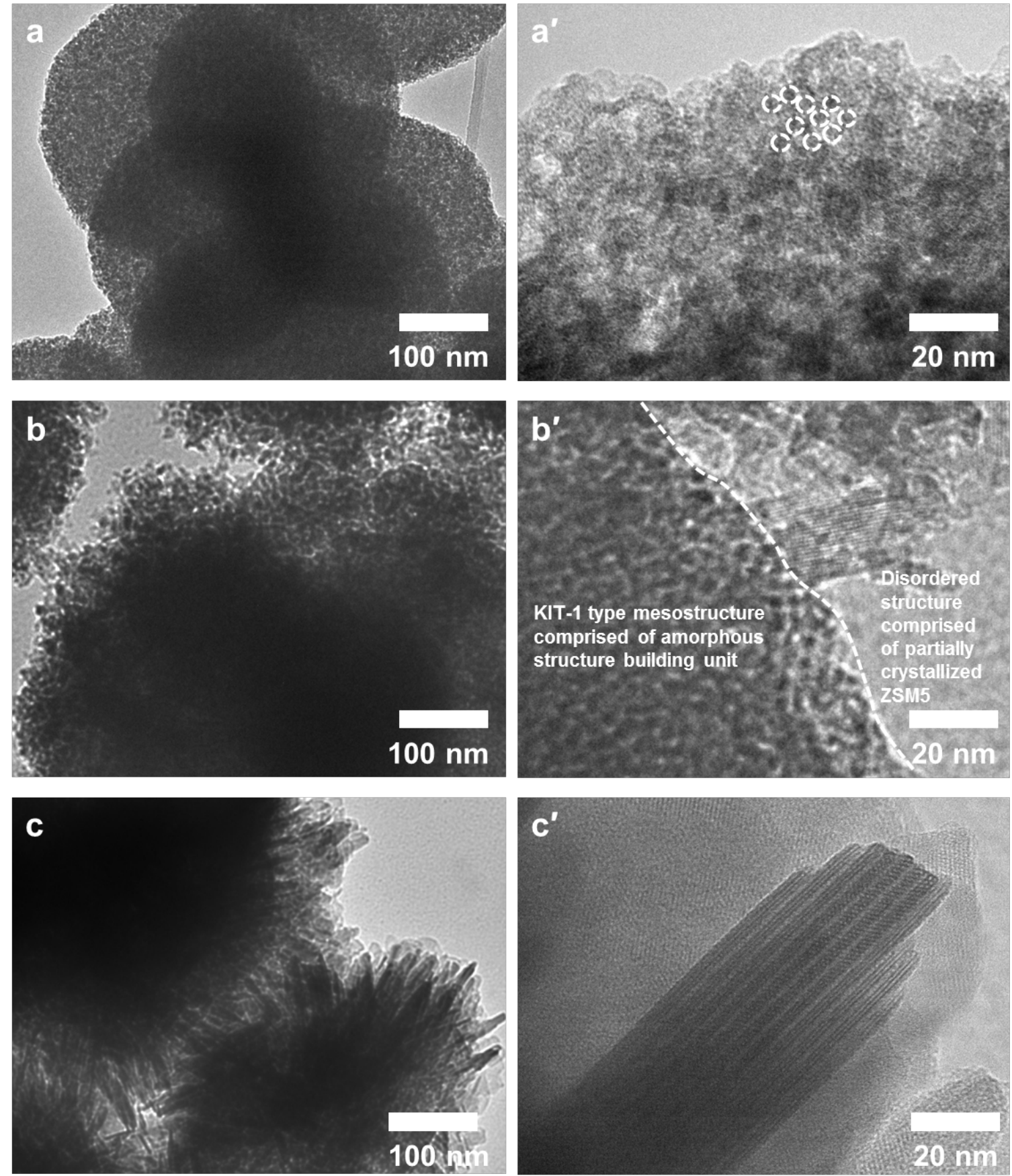

Fig. 5 TEM images of as-synthesized products obtained from precursors of $\mathrm{Si} / \mathrm{Al}=50$ at different $\mathrm{NaOH} / \mathrm{SiO}_{2}$ ratios: (a,a') 0.07, (b,b') 0.17, and (c,c') 0.27. 
At $\mathrm{NaOH} / \mathrm{SiO}_{2}=0.47$, most of the clusters were now aggregates of significantly larger plates and mostly randomly assembled, rather than organised in the interlocked manner, although each plate itself was still largely an ordered nanosheet stack. The structure of these randomly assembled plates was thus named as non-interlocked ordered nanosheet stacks or NI-ONS's.

At $\mathrm{NaOH} / \mathrm{SiO}_{2}=0.57$, the product consisted of mostly NI-ONS's, stacked on the planar dimensions. It should be pointed out that from $\mathrm{NaOH} / \mathrm{SiO}_{2}$ ratio of 0.27 to 0.57 , the planar dimension of the plates or ONS's had increased significantly from $200 \mathrm{~nm}$ to 1-2 $\mu \mathrm{m}$, while the thickness of the plates remained largely unchanged. This is thought to be controlled by the nature of the structure-directing agent used in the study, namely, the long chain hydrophobic tail of $\mathrm{C}_{22-6-6} \mathrm{Br}_{2}$ surfactant prohibited the crystal growth along the b-dimension, thus limiting the plate thickness. ${ }^{24}$ However, the excessive $\left[\mathrm{OH}^{-}\right]$accompanying the increased $\mathrm{NaOH} / \mathrm{SiO}_{2}$ ratio enhanced the crystal growth rate along the a-c dimensions, thus encouraging the planar extension of the plates.

To further study the nature of the mesostructure present in the ZSM-5 products, small angle $\mathrm{X}$ ray scattering (SAXS) patterns were collected for products of $\mathrm{Si} / \mathrm{Al}=50$ produced at different $\mathrm{NaOH} / \mathrm{SiO}_{2}$ ratios and are shown in Fig. 2A.

For the product formed at $\mathrm{NaOH} / \mathrm{SiO}_{2}=0.07$, the SAXS pattern (Fig. 2A-a) shows a faint first order scattering peak at $2 \theta=1.94^{\circ}$, corresponding to $d_{(1)}=4.6 \mathrm{~nm}$. This is believed to have resulted from the packing of nano-domains observed in the product as revealed by the TEM image (Fig. 5a').

For the product produced at $\mathrm{NaOH} / \mathrm{SiO}_{2}=0.17$, the SAXS pattern has two peaks; the first order peak at $2 \theta=1.94^{\circ}$ and the second order peak at $2 \theta=3.77^{\circ}$. This pattern is typical of a KIT-1 type mesostructure. ${ }^{36}$ Together with the TEM image of this product (Fig. 5b'), it is deduced that the product contained both KIT-1 type mesostructure comprised of amorphous structure building unit and disordered structure comprised of partially crystallized microprous structure of MFI framework.

For the product produced at $\mathrm{NaOH} / \mathrm{SiO}_{2}=0.27$, the SAXS pattern also shows two peaks, but both shifted to lower angles with the first order peak at $2 \theta=1.54^{\circ}$ and the second order peak at $2 \theta=3.65^{\circ}$. These SAXS peaks are typically originated from lamellar-type mesostructures and the intensities and sharpness of these peaks reflect the layer ordering of the lamella mesostructure. ${ }^{25}$ It is therefore believed that the intensities of both SAXS peaks were 
indicative of the degree of ordering within the nanosheet stacks of the products. Noticeably, for products produced at even higher $\mathrm{NaOH} / \mathrm{SiO}_{2}$ ratios, the pairs of the SAXS peaks appeared at very similar $2 \theta$ angles and their intensities increased progressively with increasing $\mathrm{NaOH} / \mathrm{SiO}_{2}$ ratio up to 0.47 , but decreased slightly when $\mathrm{NaOH} / \mathrm{SiO}_{2}$ reached 0.57 (Fig. 2A-c, d, e, f). These results suggest that all products had lamellar mesostructures and the ordering within the mesostructures generally increased with increasing $\mathrm{NaOH} / \mathrm{SiO}_{2}$ ratio between $0.27-0.47$. These observations are in agreement with the $V_{\text {micro }}$ results (Fig. 3 ) from the $\mathrm{N}_{2}$ sorption isotherms and SEM/TEM analysis of the products where ONSs were common structural features of these products.

It is important to point out that the d-spacing derived from the first order SAXS peak $\mathrm{d}_{(1)}$ was within the range of 5.0-5.8 $\mathrm{nm}$ for all products produced at $\mathrm{NaOH} / \mathrm{SiO}_{2} \geq 0.27$. These values are consistent with several literature reports. ${ }^{13,24-26}$ In general, $d_{(1)}$ has been found to be directly related to the inter-lamellar spacing of mesoporous materials comprised of amorphous silica, alumina or aluminasilicate such as MCM- $50 .{ }^{37}$ It was also expected to correspond to the inter-nanosheet spacing within an ordered nanosheet stack of ZSM-5. Using the method for calculating the inter-lamellar spacing of materials such as MCM-50 (interlamellar spacing $=\mathrm{d}_{(1)}$ spacing - the thickness of a lamellar layer), ${ }^{37}$ the inter-nanosheet spacing was calculated to be 3.0-3.8 nm, significantly higher than the real inter-nanosheet spacing between nanosheets within an ONS as observed from the TEM imaging analysis for all of our products. Similar results can be found in other reported work. ${ }^{13,24-26}$ A careful inspection of the detailed experimental evidence from this work and the related literature reports ${ }^{13,24-26}$ indicate that, due to the scattering of the data of the nanosheet thickness and spacing, there is a degree of uncertainty in the relationship between the SAXS $d_{(1)}$ spacing and the actual inter-nanosheet spacing within then ordered nanosheet stacks of ZSM-5, which warrants further, more detailed studies to establish the correlation.

The TEM imaging reveals a series of microstructures in the final products, changing from disorder, through KIT-1 type, to assembled lamella with an increasingly higher $\mathrm{NaOH} / \mathrm{SiO}_{2}$ ratio in the precursor. This observation, coupled with the SAXS results, suggests that the surfactant used in this study has formed different mesophases to direct the microstructure formation of the final products governed by the precursor $\left[\mathrm{OH}^{-}\right]$. As pointed out in the introduction, surfactants have been found to form different mesophases depending on the solution conditions. Typically, a surfactant such as cetrimonium bromide (CTAB) could 
undergo transformation from hexagonal, to cubic and finally to lamella mesophases with increasing $\left[\mathrm{OH}^{-}\right]$in the solution. ${ }^{30}$ Considering the chemical nature of the $\mathrm{C}_{22-6-6} \mathrm{Br}_{2}$ surfactant used in this study, it is reasonable to believe that it also underwent similar mesophase transformation from a largely disordered form at low $\left[\mathrm{OH}^{-}\right]$, through $\mathrm{KIT}-1$ type, and finally to a lamella form with progressively increasing $\left[\mathrm{OH}^{-}\right]$. These mesophases have, in turn, provided the structural directing function to assist the formation of the specific microstructures found in the final products.

Fig. 6 illustrates the $\mathrm{N}_{2}$ adsorption-desorption isotherms (A) and mesopore size distributions (B) of products of $\mathrm{Si} / \mathrm{Al}=50$ produced at different $\mathrm{NaOH} / \mathrm{SiO}_{2}$ ratios.

For the product produced at $\mathrm{NaOH} / \mathrm{SiO}_{2}=0.07$, the isotherm region between $\mathrm{p} / \mathrm{p}^{\circ}=0.5$ and 0.9 (Fig. 6A-a) displays a type $\mathrm{H} 1$ hysteresis loop, ${ }^{31}$ indicating the presence of mesopores with a certain degree of ordering in a format as revealed by the SAXS and TEM analysis. The BJH curve (Fig. 6B-a) reveals that the product possessed mesopores with a very broad size distribution centred at $\sim 16 \mathrm{~nm}$.

For the product produced at $\mathrm{NaOH} / \mathrm{SiO}_{2}=0.17$, the isotherm region between $\mathrm{p} / \mathrm{p}^{\circ}=0.42$ and 0.8 (Fig. 6A-b) exhibited a typeH4 type of hysteresis loop, ${ }^{31}$ indicating the mesopores were more like narrow slit-shaped pores with open ends. This might have arisen from the specific mesopore arrangements of the KIT-1 type mesostructure. The BJH curve (Fig. 6B-b) shows a very sharp peak at $3 \mathrm{~nm}$, indicating the mesopores had a very narrow size distribution.

As discussed in detail in Section 3.1 Fig. 1D, the product produced at $\mathrm{NaOH} / \mathrm{SiO}_{2}=0.27$ contains mostly self-interlocked ordered nanosheet stacks (SI-ONSs). The isotherms of this product display three distinctive regions, the MIC region associated with micropores at $\mathrm{p} / \mathrm{p}^{\circ}<$ 0.42; the MES-SI region for inter-crystalline mesopores between $\mathrm{p} / \mathrm{p}^{\circ}=0.42$ and 0.8 associated with the SI-ONS; and finally the MES-P region at $\mathrm{p} / \mathrm{p}^{\circ}>0.8$, associated with packing of ONSs. A relatively narrow BJH pore size distribution curve (PSD) with mesopore sizes centred at $5.4 \mathrm{~nm}$ was obtained.

For the product produced at $\mathrm{NaOH} / \mathrm{SiO}_{2}=0.37$, the isotherm region corresponding to MESSI diminished significantly (Fig. 6A-d), and the shape of the hysteresis loop seemed to exhibit both $\mathrm{H} 2$ type (interconnected mesopores) and H3 type (loosely packed pores) characteristics. The corresponding BJH curve (Fig. 6B-d) displays a relatively narrower mesopore size distribution centred at $4.4 \mathrm{~nm}$ compared with that of SI-ONS (Fig. 6B-c). 


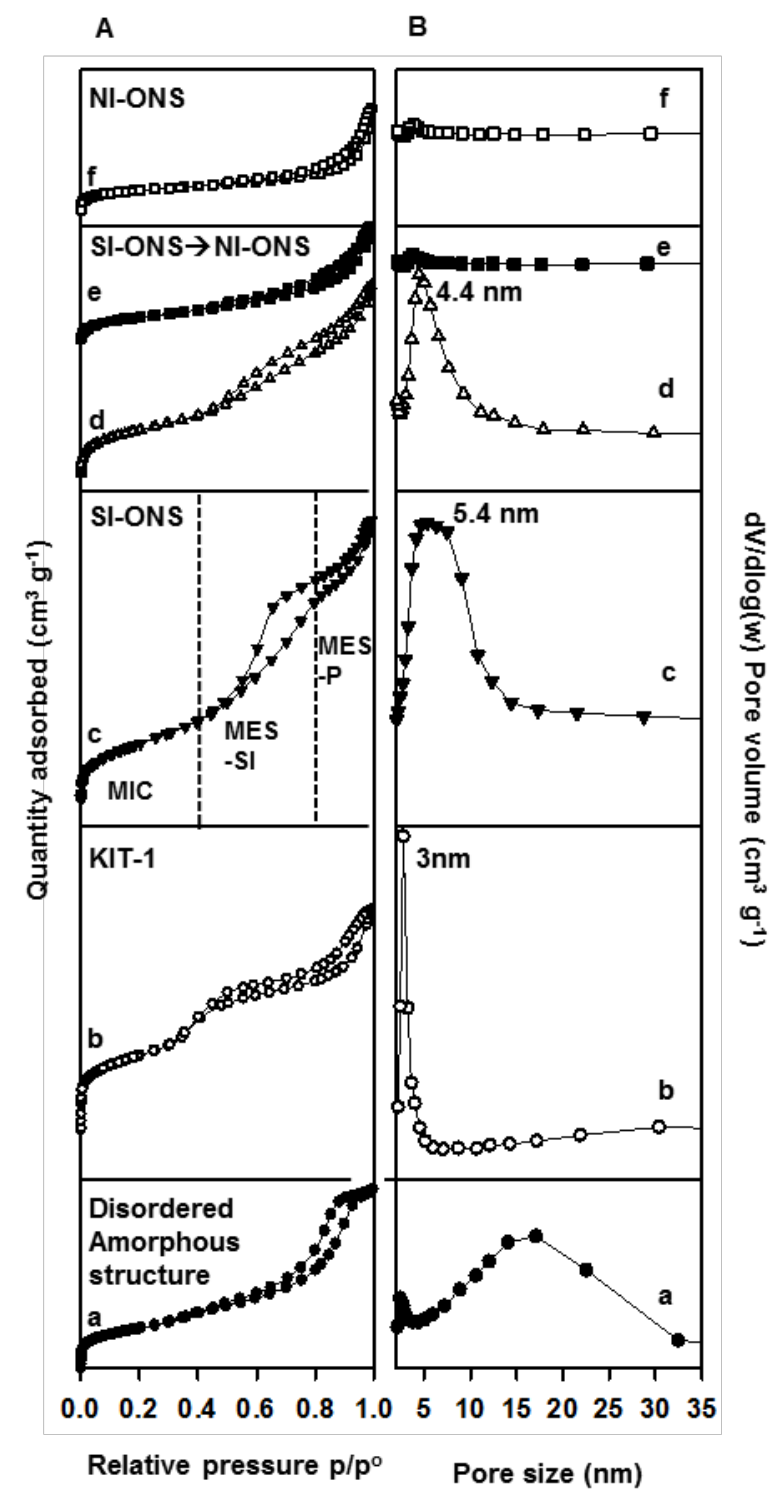

Fig. 6 A) $\mathrm{N}_{2}$-Adsorption-Desorption Isotherms, and B) BJH Pore size distributions of products obtained from precursors of $\mathrm{Si} / \mathrm{Al}=50$ at different $\mathrm{NaOH} / \mathrm{SiO}_{2}$ ratios: (a) 0.07 , (b) 0.17 , (c) 0.27 , (d) 0.37, (e) 0.47 , and (f) 0.57 .

For the products produced at even higher $\mathrm{NaOH} / \mathrm{SiO}_{2}$, there were very small areas of the MES-SI region left on their isotherms (Fig. 6A-e,f). The corresponding PSD curves shown in Fig. 6B-e,f display almost no mesopores.

Supported by the SEM/TEM analysis, the $\mathrm{N}_{2}$-sorption results shown in Fig.6 demonstrated that for $\mathrm{ZSM}-5$ of $\mathrm{Si} / \mathrm{Al}=50$, the highest mesopore volume was achieved in the product produced with $\mathrm{NaOH} / \mathrm{SiO}_{2}=0.27$, which has a microstructure consisted dominantly of SI- 
ONSs. Further increasing $\mathrm{NaOH} / \mathrm{SiO}_{2}$ from 0.27 to 0.57 resulted in a progressive reduction of mesopore volume in the resulting products, which corresponds exactly to the reduced SIONS's observed in the microstructure of these products as shown in Fig.4. These observations indicate strongly that the inter-crystalline mesopores in the ZSM-5 products were formed at the interlocked regions of SI-ONS structures.

The BET specific surface area, micropore volume $\left(\mathrm{V}_{\text {micro }}\right)$ and mesopore volume $\left(\mathrm{V}_{\text {meso }}\right)$ of the products have been extracted from the $\mathrm{N}_{2}$ adsorption-desorption isotherms. Fig. 7 illustrates the plots of BET specific surface area versus $\mathrm{NaOH} / \mathrm{SiO}_{2}$ ratio for samples of different Si/Al ratios. Several features can be noted in Fig. 7A. First of all, all curves display a maxima in the BET specific area, implying that an optimum $\mathrm{NaOH} / \mathrm{SiO}_{2}$ ratio exists for a given $\mathrm{Si} / \mathrm{Al}$ ratio. Secondly, the maxima shifted progressively to higher $\mathrm{NaOH} / \mathrm{SiO}_{2}$ ratios for samples with lower $\mathrm{Si} / \mathrm{Al}$ ratios, indicating that a high $\mathrm{NaOH} / \mathrm{SiO}_{2}$ is needed for low $\mathrm{Si} / \mathrm{Al}$ ratios in order to achieve high surface areas. It is also noted that the maximum surface area achieved was at least 30\% greater than the top line of the conventional bulk zeolites (shown between the dashed lines in Fig. 7A). In order to confirm that the large surface area was mainly due to the mesopores, the graphs of the BET specific surface area, mesopore volume and micropore volume were plotted together for each of the Si/Al ratios in Fig. 7B-a,b,c,d. It can be clearly seen that the BET specific surface area was indeed determined by the mesopore volume rather than the micropore volume for all the $\mathrm{Si} / \mathrm{Al}$ ratios. It can also be observed that the synthesis conditions which supported the formation of SI-ONS's are also supporting the formation of the highly-crystallized microporous structures (where $V_{\text {micro }} \geq 0.08 \mathrm{~cm}^{3} \mathrm{~g}^{-1}$ ).

Most significantly, it has been observed that for each given $\mathrm{Si} / \mathrm{Al}$ ratio, the product with the highest mesopore volume is exactly the one with a microstructure consisted of dominantly SIONS's. The SEM/TEM and $\mathrm{N}_{2}$-soprtion results thus unambiguously demonstrate that the inter-crystalline mesopores in the ZSM-5 products are indeed originated mainly from the selfinterlocked regions of SI-ONS's. The synthesis conditions supporting the formation of SIONSs are thus identified as the conditions to synthesize ZSM-5 with the most desirable structures comprising of both highly-crystallized microprous structure and a high amount of inter-crystalline mesopores. 

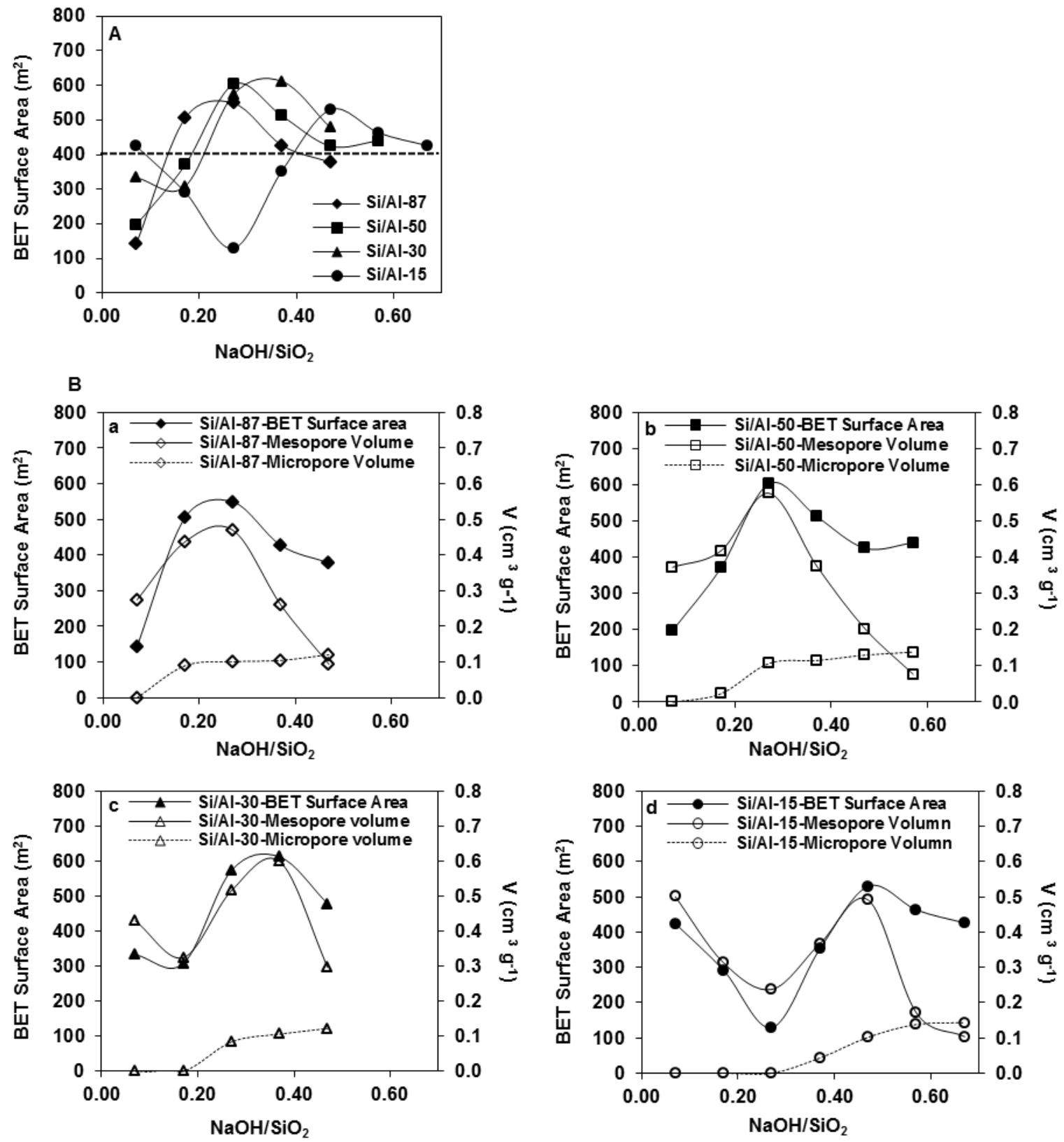

Fig. 7 A) Plots of BET surface area versus $\mathrm{NaOH} / \mathrm{SiO}_{2}$ for products of different $\mathrm{Si} / \mathrm{Al}$ ratios; B) Plots of BET surface area and pore volume $\mathrm{V}$ versus $\mathrm{NaOH} / \mathrm{SiO}_{2}$ for products of different Si/Al ratios: (a) 87, (b) 50, (c) 30, and (d) 15.

Fig. 8 shows the BJH PSDs of the products of different Si/Al ratios when SI-ONS's were formed. It can be seen that all the samples exhibited similar PSD curves with peaks centred at $5-5.5 \mathrm{~nm}$. This observation implies that under an optimum synthesis condition, SI-ONSs can be obtained with relatively identical structural properties irrespective of the $\mathrm{Si} / \mathrm{Al}$ ratio in the precursor. 


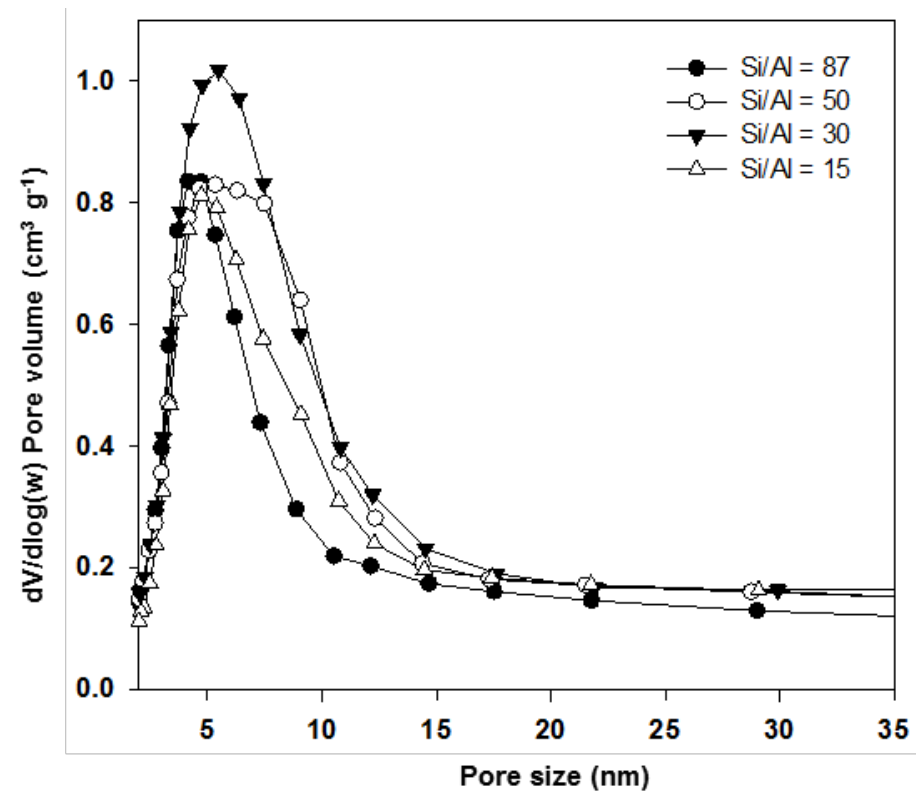

Fig. 8 BJH pore size distributions of products comprised of SI-ONS's obtained from precursors of different $\mathrm{Si} / \mathrm{Al}$ ratios.

The XRD patterns (Fig. 9A) for products of different Si/Al ratios containing mostly SI-ONS show that all the products exhibited highly crystalline microporous structure with similar peak intensities. The corresponding ${ }^{27} \mathrm{Al}$ MAS NMR spectra (Fig. 9B) illustrate that the tetrahedral $\mathrm{Al}$ peak at 55 ppm was very strong and there was almost no peak associated octahedrally coordinated $\mathrm{Al}$ species at $0 \mathrm{ppm}$. Combined XRD and NMR results suggest that almost all the $\mathrm{Al}$ species in the products are incorporated tetrahedrally in the well-established MFI framework in the products. Furthermore, the ICP-AES analysis showed that the Si/Al ratios were 76, 44, 25 and 13 for the products synthesized from precursor solutions of Si/Al ratios of 87, 50, 30 and 15, respectively, indicating that the framework Si/Al ratios in the assynthesised samples are $\sim 13 \%$ less than the nominal ratios. This level of disparity is commonly observed in published works. ${ }^{18,19,24,25}$ It is thus concluded that the composition range that supporting the formation of SI-ONSs also guarantee the formation of highly crystalline microporous structure comprised of a mostly tetrahedrally incorporated $\mathrm{Al}$ species for a wide range of $\mathrm{Si} / \mathrm{Al}$ ratios. 


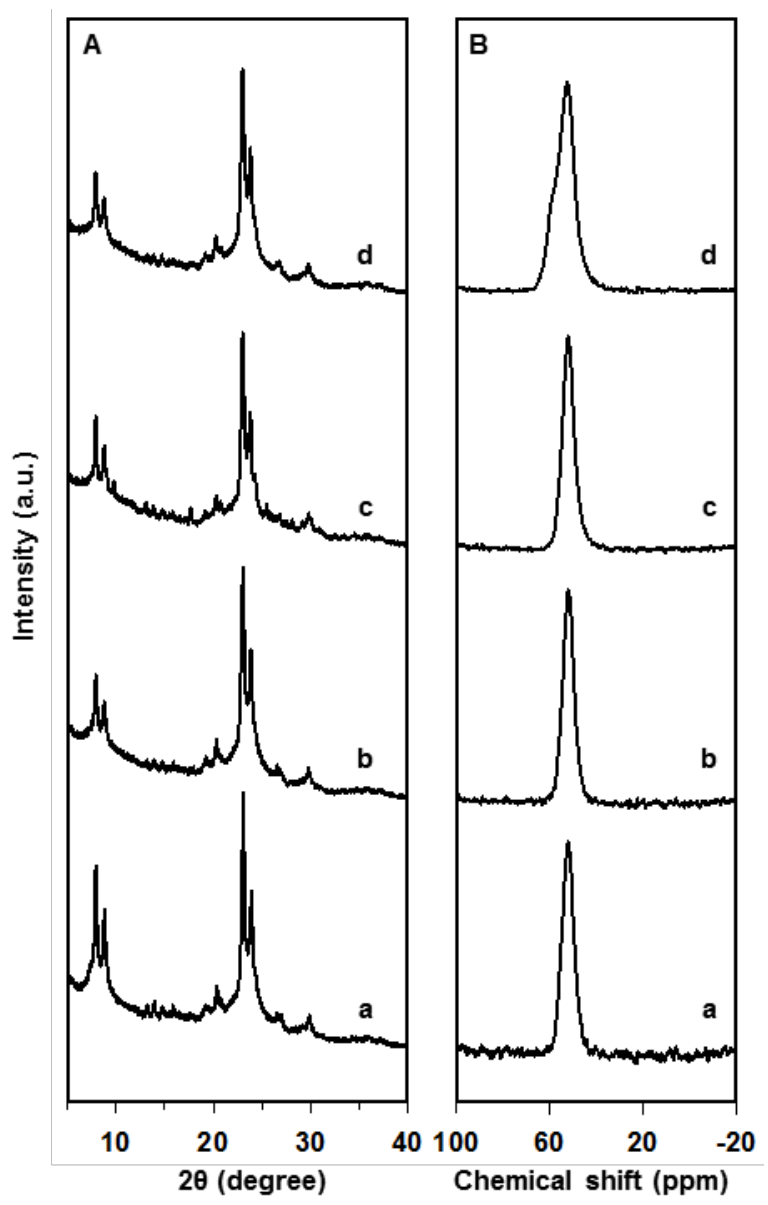

Fig. 9 Powder XRD patterns and B) ${ }^{27} \mathrm{Al}$ MAS NMR spectrum of as-synthesized products comprised of SI-ONS's obtained from precursors of Si/Al ratios of (a) 87, (b) 50, (c) 30, and (d) 15.

It is now apparent that there exists an optimum $\mathrm{NaOH} / \mathrm{SiO}_{2}$ ratio for each given $\mathrm{Si} / \mathrm{Al}$ ratio to support the formation of the most desired microstructure featuring self-interlocked ordered nanosheet stacks with well-established micropores and acid sites. The precursor composition domain to support the formation of these SI-ONS has been mapped out and presented in the ternary diagram shown in Fig. 10. 


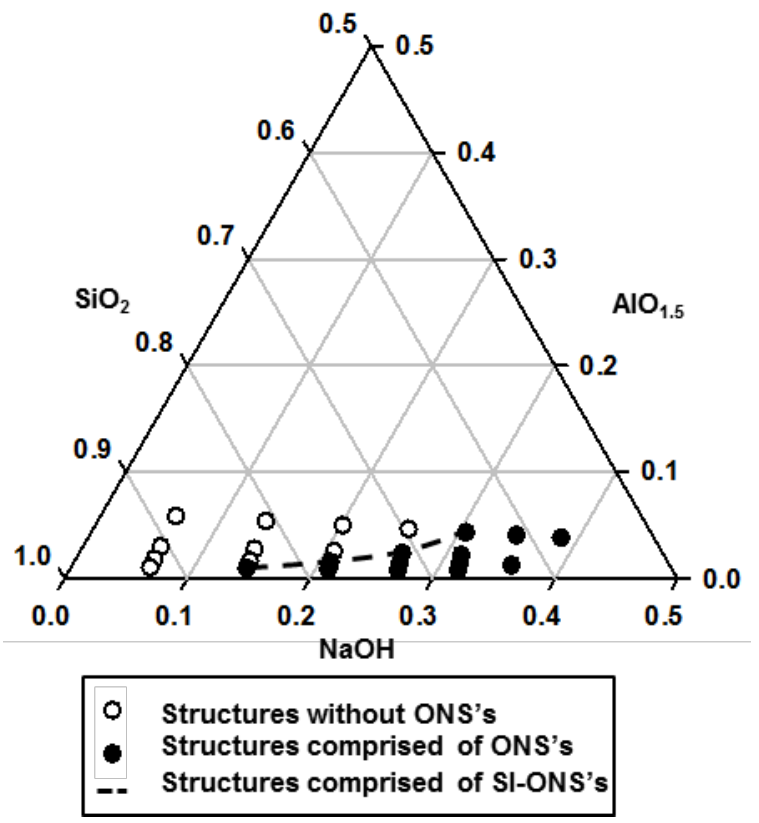

Fig.10 A ternary diagram of the molar fraction of $\mathrm{NaOH}-\mathrm{SiO}_{2}-\mathrm{AlO}_{1.5}$ system illustrating the compositional domain of the precursor from which products of different types of structure formed.

In the diagram, the open circles represent the precursor compositions where only products with amorphous or partially crystallized microstructures were formed. The filled circles represent the precursor compositions where highly crystalline ZSM-5 products were obtained. The filled circles linked by the dashed line show the formation of products with desired intercrystalline mesoporous and highly crystalline microporous structure. The ternary composition diagram established enables the synthesis of ZSM-5 with desired structural properties over a wide range of $\mathrm{Si} / \mathrm{Al}$ ratios. The $\mathrm{Si} / \mathrm{Al}$ ratio of $\mathrm{ZSM}-5$ dictates the strength and number of its active sites. This means the ZSM-5 products with desired combination of structural properties and active sites can be produced to support various specific application requirements, including the ability to provide required combination of strength and number of adsorptive sites in gas adsorption applications, to control ion-exchange selectivity and capacity in purification and separation, and to provide optimum acidity and the number of catalytic sites to support catalytic cracking, isomerisation and hydrocarbon synthesis. ${ }^{38}$ 


\section{Conclusions}

In this work, the sole surfactant $\mathrm{C}_{22-6-6} \mathrm{Br}_{2}$ was used as the structure directing agent to successfully produce mesoporous ZSM-5. It was shown that the concentration of $\mathrm{NaOH}$ in the precursor solution, $[\mathrm{NaOH}]$, played the dominant role in controlling the formation of both microporous and mesoporous structures in the final ZSM-5 products. This systematic study yielded the following significant findings:

(1) A minimum $[\mathrm{NaOH}]$ in the precursor solution is required to enable the formation of highly crystalline microporous MFI framework structure under a given synthesis condition. A higher $[\mathrm{NaOH}]$ is required for $\mathrm{ZSM}-5$ of lower $\mathrm{Si} / \mathrm{Al}$ ratios.

(2) For a given $\mathrm{Si} / \mathrm{Al}$ ratio, the crystallinity and micropore volume in the ZSM-5 product increase with increasing $[\mathrm{NaOH}]$.

(3) As $[\mathrm{NaOH}]$ in the precursor increases at a given $\mathrm{Si} / \mathrm{Al}$ ratio, there is a surfactant mesophase transformation from disordered amorphous structure, to KIT-1 mesophase, and then to the lamella mesophase. This surfactant phase transformation plays an important role in the formation of different mesostructures in the final ZSM-5 products.

(4) Depending on [NaOH], nanosheets of ZSM-5 may assemble into ordered nansheet stacks (ONS's). These ONS's can grow in an inter-locked manner forming the self-interlocked ordered nanosheet stacks (SI-ONS's). All experimental evidences converged to demonstrate that these SI-ONS's are responsible for the high volume of inter-cystalline mesopores observed in the resulting ZSM-5 products. The formation of these SI-ONS's also guarantees the formation of highly crystalline microporous structure.

(5) The composition domain for the ternary $\mathrm{NaOH}-\mathrm{SiO}_{2}-\mathrm{AlO}_{1.5}$ system was established and presented in the form of a ternary composition diagram. This provides an enabling tool to guide the synthesis of mesoporous ZSM-5 over a wide range of $\mathrm{Si} / \mathrm{Al}$ ratios, including at the challenging low $\mathrm{Si} / \mathrm{Al}$ ratio of 15 . The ability, to produce ZSM-5 over a wide range of $\mathrm{Si} / \mathrm{Al}$ ratios with desired structural properties preserved, is vitally important to keep the potential applications of this single material as wide as possible in terms of specific requirements of different $\mathrm{Si} / \mathrm{Al}$ ratios. 


\section{Acknowledgements}

The work received financial support from Australian Research Council (ARC) and Chevron Energy Technology under the ARC Linkage Projects Scheme (ARC LP100200136). The authors acknowledge the facilities, and the scientific and technical assistance of the Australian Microscopy and Microanalysis Research Facility at the Centre for Microscopy, Characterisation and Analysis of The University of Western Australia (UWA), and Professor Lianzhou Wang of The University of Queensland for the SAXS measurements. Ruicong Wei also acknowledges the postgraduate scholarships provided by UWA.

\section{References}

1. C. Baerlocher, L. B. McCusker and D. H. Olson, Atlas of zeolite framework types, Elsevier Science, 2007.

2. D. Trong On, D. Desplantier-Giscard, C. Danumah and S. Kaliaguine, Applied Catalysis A, General, 2001, 222, 299-357.

3. L. Tosheva and V. P. Valtchev, Chem. Mat., 2005, 17, 2494-2513.

4. Y. S. Tao, H. Kanoh, L. Abrams and K. Kaneko, Chem. Rev., 2006, 106, 896-910.

5. L.-H. Chen, X.-Y. Li, J. C. Rooke, Y.-H. Zhang, X.-Y. Yang, Y. Tang, F.-S. Xiao and B.-L. Su, J. Mater. Chem., 2012, 22, 17381-17403.

6. I. I. Ivanova and E. E. Knyazeva, Chemical Society Reviews, 2013, 42, 3671-3688.

7. B. Yilmaz, N. Trukhan and U. Muller, Chin. J. Catal., 2012, 33, 3-10.

8. K. Na, M. Choi and R. Ryoo, Microporous Mesoporous Mat., 2013, 15, 3-19.

9. R. Chal, C. Gerardin, M. Bulut and S. van Donk, CHEMCATCHEM, 2011, 3, 67-81.

10. K. Na, W. Park, Y. Seo and R. Ryoo, Chem. Mat., 2011, 23, 1273-1279.

11. J. Perez-Ramirez, C. H. Christensen, K. Egeblad, C. H. Christensen and J. C. Groen, Chemical Society Reviews, 2008, 37, 2530-2542.

12. H. Xin, A. Koekkoek, Q. Yang, R. v. Santen, C. Li and E. J. M. Hensen, Chemical Communications, 2009, 7590-7592.

13. W. Park, D. Yu, K. Na, K. E. Jelfs, B. Slater, Y. Sakamoto and R. Ryoo, Chem. Mat., 2011, 23, 5131-5137.

14. D. P. Serrano, J. M. Escola and P. Pizarro, Chemical Society Reviews, 2013, 42, 40044035.

15. M. Choi, H. S. Cho, R. Srivastava, C. Venkatesan, D. H. Choi and R. Ryoo, Nat. Mater., 2006, 5, 718-723. 
16. T. Bein and K. Möller*, Chemical Society Reviews, 2013, 42, 3689-3707.

17. X. Y. Zhang, D. X. Liu, D. D. Xu, S. Asahina, K. A. Cychosz, K. V. Agrawal, Y. Al Wahedi, A. Bhan, S. Al Hashimi, O. Terasaki, M. Thommes and M. Tsapatsis, Science, 2012, 336, 1684-1687.

18. L. Emdadi and D. X. Liu, Journal of Materials Chemistry A, 2014, 2, 13388-13397.

19. L. Emdadi, Y. Q. Wu, G. H. Zhu, C. C. Chang, W. Fan, T. Pham, R. F. Lobo and D. X. Liu, Chem. Mat., 2014, 26, 1345-1355.

20. A. Thomas, F. Goettmann and M. Antonietti, Chem. Mat., 2008, 20, 738-755.

21. Y. M. Fang and H. Q. Hu, J. Am. Chem. Soc., 2006, 128, 10636-10637.

22. D. P. Serrano, J. Aguado, G. Morales, J. M. Rodríguez, A. Peral, M. Thommes, J. D. Epping and B. F. Chmelka, Chem. Mat., 2009, 21, 641-654.

23. K. Cho, H. S. Cho, L.-C. de Ménorval and R. Ryoo, Chem. Mat., 2009, 21, 5664-5673.

24. M. Choi, K. Na, J. Kim, Y. Sakamoto, O. Terasaki and R. Ryoo, Nature, 2009, 461.

25. K. Na, M. Choi, W. Park, Y. Sakamoto, O. Terasaki and R. Ryoo, J. Am. Chem. Soc., 2010, 132, 4169-4177.

26. A. G. Machoke, I. Y. Knoke, S. Lopez-Orozco, M. Schmiele, T. Selvam, V. R. R. Marthala, E. Spiecker, T. Unruh, M. Hartmann and W. Schwieger, Microporous Mesoporous Mat., 2014, 190, 324-333.

27. S. M. Auerbach, K. A. Carrado and P. K. Dutta, Handbook of Zeolite Science and Technology, Taylor \& Francis, 2003.

28. J. Cejka, H. van Bekkum, A. Corma and F. Schueth, Introduction to Zeolite Molecular Sieves, Elsevier Science, 2007.

29. L.-Y. Hou, L. B. Sand, R. W. Thompson, A. I. Y. Murakami and J. W. Ward, in Studies in Surface Science and Catalysis, Elsevier, 1986, vol. Volume 28, pp. 239-246.

30. Q. S. Huo, D. I. Margolese and G. D. Stucky, Chem. Mat., 1996, 8, 1147-1160.

31. K. S. W. Sing, D. H. Everett, R. A. W. Haul, L. Moscou, R. A. Pierotti, J. Rouquerol and T. Siemieniewska, Pure Appl. Chem., 1985, 57, 603-619.

32. ISO Std., ISO 9277, 2010.

33. J. Rouquerol, P. Llewellyn and F. Rouquerol, Characterization of Porous Solids Vii Proceedings of the 7th International Symposium on the Characterization of Porous Solids (Cops-Vii), Aix-En-Provence, France, 26-28 May 2005, 2006, 160, 49-56.

34. E. P. Barrett, L. G. Joyner and P. P. Halenda, J. Am. Chem. Soc., 1951, 73, 373-380.

35. USA Pat., US 3702886 A, 1972. 
36. R. Ryoo, J. M. Kim, C. H. Ko and C. H. Shin, The Journal of Physical Chemistry, 1996, 100, 17718-17721.

37. J. S. Beck, J. C. Vartuli, W. J. Roth, M. E. Leonowicz, C. T. Kresge, K. D. Schmitt, C. T. W. Chu, D. H. Olson and E. W. Sheppard, J. Am. Chem. Soc., 1992, 114, 1083410843.

38. E. M. Flanigen, R. W. Broach and S. T. Wilson, in Zeolites in Industrial Separation and Catalysis, Wiley-VCH Verlag GmbH \& Co. KGaA, 2010, DOI: 10.1002/9783527629565.ch1, pp. 1-26. 